\title{
Medulloblastoma and Familial Adenomatous Polyposis: good prognosis and good quality of life in the long-term?
}

\author{
Maura Massimino ${ }^{1}$, Stefano Signoroni ${ }^{2}$, Luna Boschetti ${ }^{2}$, Veronica Biassoni ${ }^{3}$, Elisabetta \\ Schiavello $^{3}$, Andrea Ferrari ${ }^{4}$, Stefano Chiaravalli ${ }^{5}$, Nadia Puma ${ }^{6}$, Luca Bergamaschi ${ }^{2}$, \\ Maria Teresa Ricci ${ }^{2}$, laura cattaneo ${ }^{2}$, Giovanna Gattuso ${ }^{2}$, Francesca Buttarelli ${ }^{7}$, Francesca \\ Gianno $^{8}$, geraldina poggi ${ }^{9}$, and Marco Vitellaro ${ }^{2}$ \\ ${ }^{1}$ Istituto Nazionale Tumori \\ ${ }^{2}$ Fondazione IRCCS Istituto Nazionale dei Tumori \\ ${ }^{3}$ Fondazione IRCCS Istituto Nazionale Tumori \\ ${ }^{4}$ Istituto Nazionale Tumori, Milano \\ ${ }^{5}$ Istituto Nazionale Tumori, Milano \\ ${ }^{6}$ Fondazione IRCCS Istituto Nazionale Tumori Milano \\ ${ }^{7}$ Università La Sapienza \\ ${ }^{8}$ Sapienza University of Rome \\ ${ }^{9}$ IRCCS Eugenio Medea
}

September 11, 2020

\begin{abstract}
Introduction. Mutations of the APC (adenomatous polyposis coli) gene correlate mainly with familial adenomatous polyposis (FAP), but can occasionally be pathogenic for medulloblastoma (MBL) WNT subtype as well, the course of which has only recently been described. Methods. We retrospectively retrieved all patients with documented germline APC mutations and a centrally-reviewed diagnosis of MBL to examine the outcome of their MBL, late effects of its treatment, and further oncological events. Results. Between 2007-2016 we diagnosed and treated 6 patients, all with a pathogenic APC variant mutation, who all had MBL, classic histotype. None had metastatic disease. All patients were in complete remission a median 65 months after treatment with craniospinal irradiation at $23.4 \mathrm{~Gy}$, plus a boost on the posterior fossa/tumor bed up to 54 Gy, followed by cisplatin/carboplatin, lomustine and vincristine for a maximum of 8 courses. Five of 6 diagnostic revised MRI were suggestive of the WNT molecular subgroup typical aspects. Four of 6 patients had a positive family history of FAP, while gastrointestinal symptoms prompted its identification in the other 2 cases. Four patients had developed other tumors (desmoid, MELTUMP, melanoma, pancreatoblastoma, thyroid Tir3) from 5 to 7 years after MBL. Discussion. Our data confirm a good prognosis for patients with MBL associated with FAP. Patients' secondary tumors may or may not be related to their syndrome or treatment, but warrant adequate attention when planning shared guidelines for these patients.
\end{abstract}

\section{Introduction}

APC (adenomatous polyposis coli) is a tumor suppressor gene that has multiple important functions. It encodes a protein that is an essential component of the WNT signaling pathway; together with axin and GSK3beta, it regulates the intracellular localization and degradation of beta-catenin, influencing cell adhesion and migration capacity and it controls cell replication.

Sporadic (non-hereditary) somatic mutations or loss of APC gene function are early events leading to colon cancer $^{1}$. Germline mutations in the APC gene are responsible instead for a form of hereditary predispo- 
sition to the onset of colic adenomas known as familial adenomatous polyposis (FAP). Patients with FAP characteristically develop numerous intestinal polyps (adenomas). According to the guidelines ${ }^{2-5}$, they need intensive endoscopic surveillance from 10-14 years of age, and prophylactic total colectomy no later than the second decade of life to reduce the risk of colorectal carcinoma (CRC). The recommended options for prophylactic total colectomy in this setting are: total rectal preservation and ileorectal anastomosis (TC/IRA) or total proctocolectomy with ileoanal canal anastomosis (PC/IPAA). The choice is dictated mainly by the number and distribution of polyps in the rectum ([?] or $<30)$.

Patients with FAP can also develop lesions outside the colon, including gastric and duodenal polyps, desmoid tumors, thyroid tumors, hepatoblastomas, epidermoid cysts, osteomas and congenital hypertrophy of the retinal pigment epithelium ${ }^{6}$.

The occurrence of brain tumors in FAP patients remains rare (in no more than $1 \%$ of cases), MBL being the most likely central nervous system tumor to be described in carriers of APC germline pathogenic variants, typically in pediatric age ${ }^{7}$. The molecular changes underlying MBL are the same as those involved in the morphogenesis of the cerebellum, i.e. the Sonic Hedgehog pathway (involved in controlling the normal proliferation of cerebellar granules) and the WNT pathway (including APC and beta-catenin) ${ }^{8}$. Some of the most significant insight on the biological pathways involved in the pathogenesis of MBL has come from investigating rare family syndromes that predispose to its onset. APC is an essential component of the physiological activation of the WNT/Wg pathway, necessary for the normal development of neural cells. Activation of this pathway identifies a unique molecular subgroup of MBL with distinct DNA methylation patterns, gene expression profiles, genomic anomalies, and clinical outcome ${ }^{9}$. In independent biological studies based on clinical trials ${ }^{10}$, this subgroup exhibits a particular behavior and has been found associated with a favorable clinical outcome (with an overall survival exceeding 90\%). WNT-medulloblastomas lack a blood-brain barrier and this feature may explain why these tumors are highly susceptible to chemotherapy and radiotherapy ${ }^{11}$. The overall good prognosis of WNT-medulloblastoma has solicited a hypothesis for treatment de-escalation ongoing in many trials and concerning both total dose of craniospinal irradiation (CSI) and total duration of treatment with reduced number of adjuvant chemotherapy courses ${ }^{12-13}$.

Although WNT/Wg-positive MBL tend to have classical histological features in the vast majority of cases (or may rarely resemble large cell/anaplastic lesions) and arise in older children, they are hard to distinguish from other tumors with similar clinical and histological characteristics, and have to be identified at the molecular level.

The aim of the present study was to describe the outcome of patients with MBL and FAP with APC germline pathogenic mutations treated for both conditions at our institute in the last 10 years.

\section{Methods}

From the years 2007 to 2016 we retrieved all records of patients with MBL and FAP, adopting the following main inclusion criteria:

1. documented germline APC mutations

2. centrally-reviewed histopathological diagnosis of MBL;

3. no age limit;

4. one or more conventional brain MRI studies, reviewed by the authors (LC; AE);

5. genetic counseling for FAP, and documentation and assessment of family history.

For two patients, who were probands, APC germline analysis was performed on genomic DNA extracted from blood samples by Sanger direct sequencing. Moreover, large deletions or duplications were investigated by Multiplex Ligation Dependent Probe Amplification (MLPA). Four patients, who were not probands, were submitted to predictive genetic test, in order to find the mutation present in the family; 
MRI studies were reviewed according to Patay criteria ${ }^{14}$. Briefly, on the basis of anatomic lesion patterns, Patay distinguished 4 location-based subtypes: 1) midline-intraventricular as subtype A, 2) midlineextraventricular as subtype B, 3) off-midline-intraventricular as subtype C, and 4) off-midline- extraventricular as subtype D, which represent a continuum. WNT-sub-group MBLs are in fact close to the midline yet there are also lateralized tumors originating from structures around the foramen of Luschka .

By examining these patients' diagnostic and treatment data, we aimed to: i) describe their progression-free survival and overall survival; ii) confirm the favorable prognosis reported in the recent literature ${ }^{15}$, and describe the potential (clinical, therapeutic, pathological and molecular) prognostic factors associated with successful treatment; and iii) examine in depth the complex hereditary genetic mechanism behind the onset and course of MBL in these patients.

We also considered acute, i.e. craniospinal irradiation duration, chemotherapy courses received, total drug doses administered, and long-term toxicities, i.e. endocrine and neurocognitive deficits, of the treatments administered. All survivors' current state of health and social status was reported with a view (if possible and judged necessary) to reducing the post-surgical treatment of this particular group of MBL in the light of patients' prognosis and the toxicity they experienced.

Oncological disease-free survival after the diagnosis of MBL was calculated with Kaplan Meier methods.

The study was approved by our institution's independent ethical committee (prot. 166/20). Patients or parents gave their consent to this analysis.

\section{Results}

Patients' medulloblastoma-related features

Six patients ( 5 of them females) were diagnosed between 2007 and 2016 and met our inclusion criteria. They were a median 10 years old (range 6-26 years) at medulloblastoma diagnosis. All patients presented at diagnosis with a clinical picture correlating with the tumor site (i.e. cerebellar deficits, endocranial hypertension, strabismus). None of them had had MRI before the suspect of brain tumor diagnosis for surveillance purposes .

The original MRI findings could be retrieved for review in $5 / 6$ cases. Tumors were classified on the grounds of site, T2-weighted and DWI signal intensity, and contrast enhancement in accordance with the classification of WNT medulloblastoma proposed by Patay et al and already above summarized ${ }^{12}$. All tumors were located in the IV ventricle and characterized by uneven T2 hyperintensity, patchy contrast enhancement, and low ADC levels on DWI. All. Two were subtype A, and 3 were subtype B. Hydrocephalus was absent in 3 and present in 2 cases (Figure 1, case 5 not shown).

All patients underwent complete surgical excision of their tumors, which were all attributed to classic histotype and WNT subtype since WNT is deregulated where there is a germline APC pathogenetic mutation For all patients Beta-catenin immunostaining was assessed in tumoral tissue. Nuclear positivity at immunohistochemistry was found in $2 / 6$ patients' samples.

All patients were homogeneously treated irrespective of age under or over 18 years, as already reported ${ }^{16}$. Importantly, all patients received craniospinal irradiation (CSI) up to a total dose of 23.4 Gy, and a boost to the posterior fossa (in 3 patients) or tumor bed (in the other 3) up to a total dose of 54 Gy, delivered in fractions of $1.8 \mathrm{~Gy}$, without any interruption due to acute side-effects of hematological toxicity (table 1).

In one patient (who was 26 years old at diagnosis), the post-operative schedule including cisplatin, vincristine and lomustine was changed - replacing cisplatin with carboplatin and omitting vincristine - due to ototoxicity after the second course and severe peripheral neurotoxicity with gait impairment .

All patients were in complete remission at 44-142 months after diagnosis (median 65 months) and were in active follow-up at the time of this report. 
Late effects - Three patients had hypoacusia for acute tones, three had hypothyroidism (accompanied by thyroid nodules in 2 cases), two had growth hormone deficits, and five had vitamin D deficiency. One patient was married and having fertility treatment.

Three patients were still in main stream school, with special education program and extra-help teacher in one case each (at MBL diagnosis 6 and 10 years old, respectively), while the third one did not need education tailored program or help (6 years old at diagnosis).

One patient, 13 years old at diagnosis, was attending university; one, 12 years old at diagnosis, was working after completing a professional course and one, 26 years old at diagnosis, had a university degree, was married and stayed at home, fully independent. Full Intelligence Quotients (FIQ) were available for 5 patients after 2-7 years from diagnosis (table 1).

Table 1 shows also each patient's oncological history after treatment for MBL. One patient developed a melanocytic tumor of uncertain malignant potential (MELTUMP), one a melanoma, another a thyroid nodule (classified as TIR3, i.e. uncertain malignancy, after needle biopsy) and a pancreatoblastoma a mean 6 years after MBL.

Figure 2 shows patients subsequent oncological disease-free survival, which was $50 \%$ at 5 years.

Patients' FAP-related features

All patients harbored a pathogenic germline variant of the APC gene that was responsible for a truncated protein in five cases and the complete loss of the protein in one. Two of the 6 patients were probands, and FAP was diagnosed after the onset of gastrointestinal symptoms ( 8 years after treatment for MBL in one case). The other four patients belonged to families with already genetically determined polyposis. Two patients underwent total colectomy with IRA, while four have yet to undergo surgery. One of the patients who had total colectomy developed an intra-abdominal desmoid tumor 4 years after this prophylactic surgery.

Patients' FAP-related family histories are shown in Table 3. Five of the 6 patients had a family history of polyposis, three had a family history of CRC, and none of the patients had a family history of CNS tumors. Other tumors were described in the families of three patients.

\section{Discussion}

APC somatic mutations are not generally found in sporadic MBL, but this tumor may be associated with patients harboring the APC germline pathogenic mutations that cause FAP syndrome ${ }^{17}$. APC gene mutations generally start from a KRAS proto-oncogene point mutation with DNA hypomethylation activating the proto-oncogene. This is followed by a loss of the APC alleles that serve as a tumor suppressor gene. MBL associated with FAP syndrome comes from neural stem cells containing the homozygous APC mutation ${ }^{18}$.

MBL accounts for $80 \%$ of the brain tumors found in patients with FAP, a condition associated with a 7 -fold relative lifetime risk of any brain tumor, and with a 90 times higher risk of $\mathrm{MBL}^{19}$.

The molecular subtype in the context of FAP is Wnt/Wg. APC mutations are involved in around $7 \%$ of $\mathrm{Wnt} / \mathrm{Wg}$ molecular subtype $\mathrm{MBL}^{20-25}$. It is noticeable that in our series, some cases despite APC germline mutations do not show nuclear $\beta$-catenin accumulation, but it must be underlined that there are some limits of immunohistochemistry which make the technique not always reliable ${ }^{26-27}$. These patients' radiological features were superimposable on those reported by Patay in the context of Wnt molecular subgroup MBL ${ }^{14}$ and later confirmed by other authors ${ }^{28}$. There are no guidelines for brain tumor surveillance in the context of FAP, probably because there are still no registries available to consult that reliably show how many people with inherited or sporadic colorectal cancer develop MBL, or vice versa ${ }^{29}$. In members of a family with FAP who do not yet have polyposis, neurological symptoms should prompt radiological examination of the CNS because brain tumors manifest before the polyposis is diagnosed in more than one in two FAP patients ${ }^{30}$. This was also the case in two of our six patients. A major effort by the SIOP to move in this direction is in progress as part of the PNET5 trial ${ }^{12}$, with the creation of a registry for all patients with MBL harboring constitutional genetic mutations, including APC. 
What we are still lacking, however, is therapeutic guidelines that take into account both the good outcomes reported in a handful of more recent papers ${ }^{15}$ and the genetic fragility of these patients. They spontaneously develop many different types of tumor and are obviously more susceptible to secondary tumors after adjuvant treatment for MBL. It is sadly remarkable that the only death of a patient, in the series recently reported by a cooperative French group ${ }^{15}$, was due to a triton tumor 14 years after MBL had been diagnosed.

As already underlined, patients with Wnt-MBL are currently treated with de-escalating protocols aiming at maintaining good outcome with reduced late effects ${ }^{12-13}$. This FAP patient subgroup is even more fragile, deserving special attention in their disease story. It is moreover to note that a very recent paper has reported a meta-analysis on Wnt -MBL relapses showing the usefulness of adjuvant cyclofosfamide in reducing relapses ${ }^{31}$.

In our smaller but single-institution series, apart from desmoid and thyroid tumors, three patients developed other three tumors possibly unrelated to FAP, despite having received lower doses of CSI than the French series, and standard chemotherapy.

Few data characterize the cognitive abilities of individuals with FAP but the role of the APC protein in the development of the central nervous system is well known ${ }^{32}$ and a very recent paper has underlined the significantly lower performance on IQ and in a variety of neurocognitive functions in a population of 24 subjects compared to non-FAP pairs ${ }^{33}$. The results of our small series in term of cognitive performances, FIQ and social life are therefore not only to be attributed to MBL and its treatment but also to the persasive activity of FAp ${ }^{33}$

Collecting these now better-defined cases of MBL in patients with FAP will broaden our understanding of their MBL outcome and hopefully enable their better-tailored treatment and rehabilitation.

Disclosure statement . No relevant interest to be disclosed

\section{Acknowledgments}

Associazione Bianca Garavaglia Onlus, Busto Arsizio, Italy; LILT (Lega Italiana per la Lotta contro i Tumori), Milano, Italy; Con Lorenzo per mano Onlus, Como, Italy

\section{References}

1. Yurgelun MB, Kulke MH, Fuchs CS, Allen BA, Uno H, Hornick JL, Ukaegbu CI, Brais LK, McNamara PG, Mayer RJ, Schrag D, Meyerhardt JA, Ng K, Kidd J, Singh N, Hartman AR, Wenstrup RJ, Syngal S. Cancer susceptibility gene mutations in individuals with colorectal cancer. J Clin Oncol. 2017 Apr 1;35(10):1086-1095. doi: 10.1200/JCO.2016.71.0012

2. https://www.cancer.net/cancer-types/familial-adenomatous-polyposis

3. Winawer S, Fletcher R, Rex D, Bond J, Burt R, Ferrucci J, Ganiats T, Levin T, Woolf S, Johnson D, Kirk L, Litin S, Simmang C; Gastrointestinal Consortium Panel. Colorectal cancer screening and surveillance: clinical guidelines and rationale. Update based on new evidence. Gastroenterology. 2003 Feb;124(2):544-60. doi: 10.1053/gast.2003.50044

4. Vitellaro M, Bonfanti G, Sala P, Poiasina E, Barisella M, Signoroni S, Mancini A, Bertario L. Laparoscopic colectomy and restorative proctocolectomy for familial adenomatous polyposis. Surg Endosc. 2011 Jun;25(6):1866-75. doi: 10.1007/s00464-010-1478-z

5. Gupta S, Provenzale D, Llor X, Halverson AL, Grady W, Chung DC, Haraldsdottir S, Markowitz AJ, Slavin TP Jr, Hampel H; CGC, Ness RM, Weiss JM, Ahnen DJ, Chen LM, Cooper G, Early DS, Giardiello FM, Hall MJ, Hamilton SR, Kanth P, Klapman JB, Lazenby AJ, Lynch PM, Mayer RJ, Mikkelson J; CGC, Peter S, Regenbogen SE, Dwyer MA; CGC, Ogba N. NCCN Guidelines Insights: Genetic/Familial High-Risk Assessment: Colorectal, Version 2.2019. J Natl Compr Canc Netw. 2019 Sep 1;17(9):1032-1041. doi: 10.6004/jnccn.2019.0044

6. Nosé V. Familial Cancer Syndromes in Diagnostic Pathology: E-Book - 2020; 719

7. Northcott PA, Robinson GW, Kratz CP, Mabbott DJ, Pomeroy SL, Clifford SC, Rutkowski S, Ellison DW, Malkin D, Taylor MD, Gajjar A, Pfister SM. Medulloblastoma. Nat Rev Dis Primers. 2019 Feb 
14;5(1):11. doi: 10.1038/s41572-019-0063-6

8. Roussel MF, Hatten ME. Cerebellum development and medulloblastoma. Curr Top Dev Biol. 2011;94:235-82. doi: 10.1016/B978-0-12-380916-2.00008-5

9. Northcott PA, Dubuc AM, Pfister S, Taylor MD. Molecular subgroups of medulloblastoma. Expert Rev Neurother. 2012 Jul;12(7):871-84. doi: 10.1586/ern.12.66

10. Fattet S, Haberler C, Legoix P, Varlet P, Lellouch-Tubiana A, Lair S, Manie E, Raquin MA, Bours D, Carpentier S, Barillot E, Grill J, Doz F, Puget S, Janoueix-Lerosey I, Delattre O. Beta-catenin status in paediatric medulloblastomas: correlation of immunohistochemical expression with mutational status, genetic profiles, and clinical characteristics. J Pathol. 2009 May;218(1):86-9

11. Phoenix TN, Patmore DM, Boop S, et al. : Medulloblastoma Genotype Dictates Blood Brain Barrier Phenotype. Cancer Cell. 2016;29:508-22. 10.1016/j.ccell.2016.03.002

12. https://clinicaltrials.gov/ct2/show/study/NCT02066220

13. https://clinicaltrials.gov/ct2/show/NCT01878617

14. Patay Z, DeSain LA, Hwang SN, Coan A, Li Y, Ellison DW. MR imaging characteristics of winglesstype-subgroup pediatric medulloblastoma. AJNR Am J Neuroradiol. 2015 Dec;36(12):2386-93. doi: 10.3174/ajnr.A4495

15. Surun A, Varlet P, Brugières L, Lacour B, Faure-Conter C, Leblond P, Bertozzi-Salomon AI, Berger C, André N, Sariban E, Raimbault S, Prieur F, Desseigne F, Zattara H, Guimbaud R, Polivka M, Delisle MB, Vasiljevic A, MaurageCA, Figarella-Branger D, Coulet F, Guerrini-Rousseau L, Alapetite C, Dufour C,Colas C, Doz F, Bourdeaut F. Medulloblastomas associated with an APC germline pathogenic variant share the good prognosis of CTNNB1-mutated medulloblastomas. Neuro Oncol. 2020 Jan 11;22(1):128-138. doi: 10.1093/neuonc/noz154

16. Massimino M, Sunyach MP, Barretta F, Gandola L, Garegnani A, Pecori E, Spreafico F, BonnevilleLevard A, Meyronet D, Mottolese C, Boschetti L, Biassoni V, Schiavello E, Giussani C, Carrabba G, Diletto B, Pallotti F, Stefini R, Ferrari A, Terenziani M, Casanova M, Luksch R, Meazza C, Podda M, Chiaravalli S, Puma N, Bergamaschi L, Morosi C, Calareso G, Giangaspero F, Antonelli M, Buttarelli FR, Frappaz D. Reduced-dose craniospinal irradiation is feasible for standard-risk adult medulloblastoma patients. J Neurooncol. 2020 Jun 21. doi:10.1007/s11060-020-03564-y

17. Khattab A, Monga DK. Turcot syndrome. [Updated 2020 Jun 29]. In: StatPearls [Internet]. Treasure Island (FL): StatPearls Publishing; 2020 Jan-.

18. Crawford JR, MacDonald TJ, Packer RJ. Medulloblastoma in childhood: new biological advances. Lancet Neurol. 2007 Dec;6(12):1073-85. doi: 10.1016/S1474-4422(07)70289-2

19. Groen EJ, Roos A, Muntinghe FL, Enting RH, de Vries J, Kleibeuker JH, Witjes MJ, Links TP, van Beek AP. Extra-intestinal manifestations of familial adenomatous polyposis. Ann Surg Oncol. 2008 Sep;15(9):2439-50. doi: 10.1245/s10434-008-9981-3

20. Zurawel RH, Chiappa SA, Allen C, Raffel C. Sporadic medulloblastomas contain oncogenic beta-catenin mutations. Cancer Res. 1998 Mar 1;58(5):896-9

21. Eberhart CG, Tihan T, Burger PC. Nuclear localization and mutation of beta-catenin in medulloblastomas. J Neuropathol Exp Neurol. 2000 Apr;59(4):333-7. doi: 10.1093/jnen/59.4.333

22. Huang H, Mahler-Araujo BM, Sankila A, Chimelli L, Yonekawa Y, Kleihues P, Ohgaki H. APC mutations in sporadic medulloblastomas. Am J Pathol. 2000 Feb;156(2):433-7. doi: 10.1016/S00029440(10)64747-5

23. Dahmen RP, Koch A, Denkhaus D, Tonn JC, Sörensen N, Berthold F, Behrens J, Birchmeier W, Wiestler OD, Pietsch T. Deletions of AXIN1, a component of the WNT/wingless pathway, in sporadic medulloblastomas. Cancer Res. 2001 Oct 1;61(19):7039-43

24. Koch A, Waha A, Tonn JC, Sörensen N, Berthold F, Wolter M, Reifenberger J, Hartmann W, Friedl W, Reifenberger G, Wiestler OD, Pietsch T. Somatic mutations of WNT/wingless signaling pathway components in primitive neuroectodermal tumors. Int J Cancer. 2001 Aug 1;93(3):445-9. doi: 10.1002/ijc. 1342

25. Baeza N, Masuoka J, Kleihues P, Ohgaki H. AXIN1 mutations but not deletions in cerebellar medulloblastomas. Oncogene. 2003 Jan 30;22(4):632-6. doi: 10.1038/sj.onc.1206156 
26. Waszak SM, Northcott PA, Buchhalter I, Robinson GW, Sutter C, Groebner S, Grund KB, Brugières L, Jones DTW, Pajtler KW, Morrissy AS, Kool M, Sturm D, Chavez L, Ernst A, Brabetz S, Hain M, Zichner T, Segura-Wang M, Weischenfeldt J, Rausch T, Mardin BR, Zhou X, Baciu C, Lawerenz C, Chan JA, Varlet P, Guerrini-Rousseau L, Fults DW, Grajkowska W, Hauser P, Jabado N, Ra YS, Zitterbart K, Shringarpure SS, De La Vega FM, Bustamante CD, Ng HK, Perry A, MacDonald TJ, Hernáiz Driever P, Bendel AE, Bowers DC, McCowage G, Chintagumpala MM, Cohn R, Hassall T, Fleischhack G, Eggen T, Wesenberg F, Feychting M, Lannering B, Schüz J, Johansen C, Andersen TV, Röösli M, Kuehni CE, Grotzer M, Kjaerheim K, Monoranu CM, Archer TC, Duke E, Pomeroy SL, Shelagh R, Frank S, Sumerauer D, Scheurlen W, Ryzhova MV, Milde T, Kratz CP, Samuel D, Zhang J, Solomon DA, MarraM, Eils R, Bartram CR, von Hoff K, Rutkowski S, Ramaswamy V, Gilbertson RJ, Korshunov A, Taylor MD, Lichter P, Malkin D, Gajjar A, Korbel JO, Pfister SM. Spectrum and prevalence of genetic predisposition in medulloblastoma: a retrospective genetic study and prospective validation in a clinical trial cohort. Lancet Oncol. 2018 Jun;19(6):785-798. doi: 10.1016/S1470-2045(18)30242-0

27. Silva R, Marie SK, Uno M, Matushita H, Wakamatsu A, Rosemberg S. CTNNB1, AXIN1 and APC expression analysis of different medulloblastoma variants. Clinics 2013;68(2):167-172

28. Perreault S, Ramaswamy V, Achrol AS, Chao K, Liu TT, Shih D, Remke M, Schubert S, Bouffet E, Fisher PG, Partap S, Vogel H, Taylor MD, Cho YJ, Yeom KW. MRI surrogates for molecular subgroups of medulloblastoma. AJNR Am J Neuroradiol. 2014 Jul;35(7):1263-9. doi: 10.3174/ajnr.A399

29. Kim B, Tabori U, Hawkins C. An update on the CNS manifestations of brain tumor polyposis syndromes. Acta Neuropathol. 2020 Apr;139(4):703-715. doi: 10.1007/s00401-020-02124-y

30. Groen EJ, Roos A, Muntinghe FL, Enting RH, de Vries J, Kleibeuker JH, Witjes MJ, Links TP, van Beek AP. Extra-intestinal manifestations of familial adenomatous polyposis. Ann Surg Oncol. 2008 Sep;15(9):2439-50. doi: 10.1245/s10434-008-9981-3

31. Nobre L, Zapotocky M, Khan S, Fukuoka K, Fonseca A, McKeown T, Sumerauer D, Vicha A, Grajkowska WA, Trubicka J, Li KKW, Ng HK, Massimi L, Lee JY, Kim SK, Zelcer S, Vasiljevic A, Faure-Conter C, Hauser P, Lach B, van Veelen-Vincent ML, French PJ, Van Meir EG, Weiss WA, Gupta N, Pollack IF, Hamilton RL, Nageswara Rao AA, Giannini C, Rubin JB, Moore AS, Chambless LB, Vibhakar R, Ra YS, Massimino M, McLendon RE, Wheeler H, Zollo M, Ferruci V, Kumabe T, Faria CC, Sterba J, Jung S, López-Aguilar E, Mora J, Carlotti CG, Olson JM, Leary S, Cain J, Krskova L, Zamecnik J, Hawkins CE, Tabori U, Huang A, Bartels U, Northcott PA, Taylor MD, Yip S, Hansford JR, Bouffet E, Ramaswamy V. Pattern of Relapse and Treatment Response in WNT-Activated Medulloblastoma. Cell Rep Med 2020;1:100038. doi: 10.1016/j.xcrm.2020.100038

32. Rosenberg MM, Yang F, Giovanni M, Mohn JL, Temburni MK, Jacob MH. Adenomatous polyposis coli plays a key role, in vivo, in coordinating assembly of the neuronal nicotinic post synaptic complex. Mol Cell Neurosci 2008;38:138-52

Cruz-Correa MR, Sala AC, Cintrón B, Hernández J, Olivera M, Cora A, Moore CM, Luciano CA, SotoSalgado M, Giardiello FM, Hooper SR. Ubiquitous neurocognitive dysfunction in familial adenomatous polyposis: proof-of-concept of the role of APC protein in neurocognitive function. Hered Cancer Clin Pract. 2020;18:4. doi: $0.1186 /$ s13053-020-0135-3

\section{Figure legends}

Figure 1. Brain MRI in cases 1-4. T2-wi (A,B), ADC (C), T1-wi after contrast medium (D) showing tumors in the posterior fossa located in the fourth ventricle. In cases 1-3, the masses appear to be gross midline, with no definite laterality. Note involvement of the left (case 1) and right (case 2) postero-lateral recesses of the fourth ventricle in subtype B (arrows), and of the right antero-lateral recess of the fourth ventricle in subtype A (arrowheads in case 3). In case 4, the tumor is midline, with no obvious laterality. Subtype A is the most central of all WNT medulloblastomas (ref Patay Z et al 2015). All tumors show similar signal abnormalities and enhancement patterns.

Figure 2. Survival free of other oncological events 

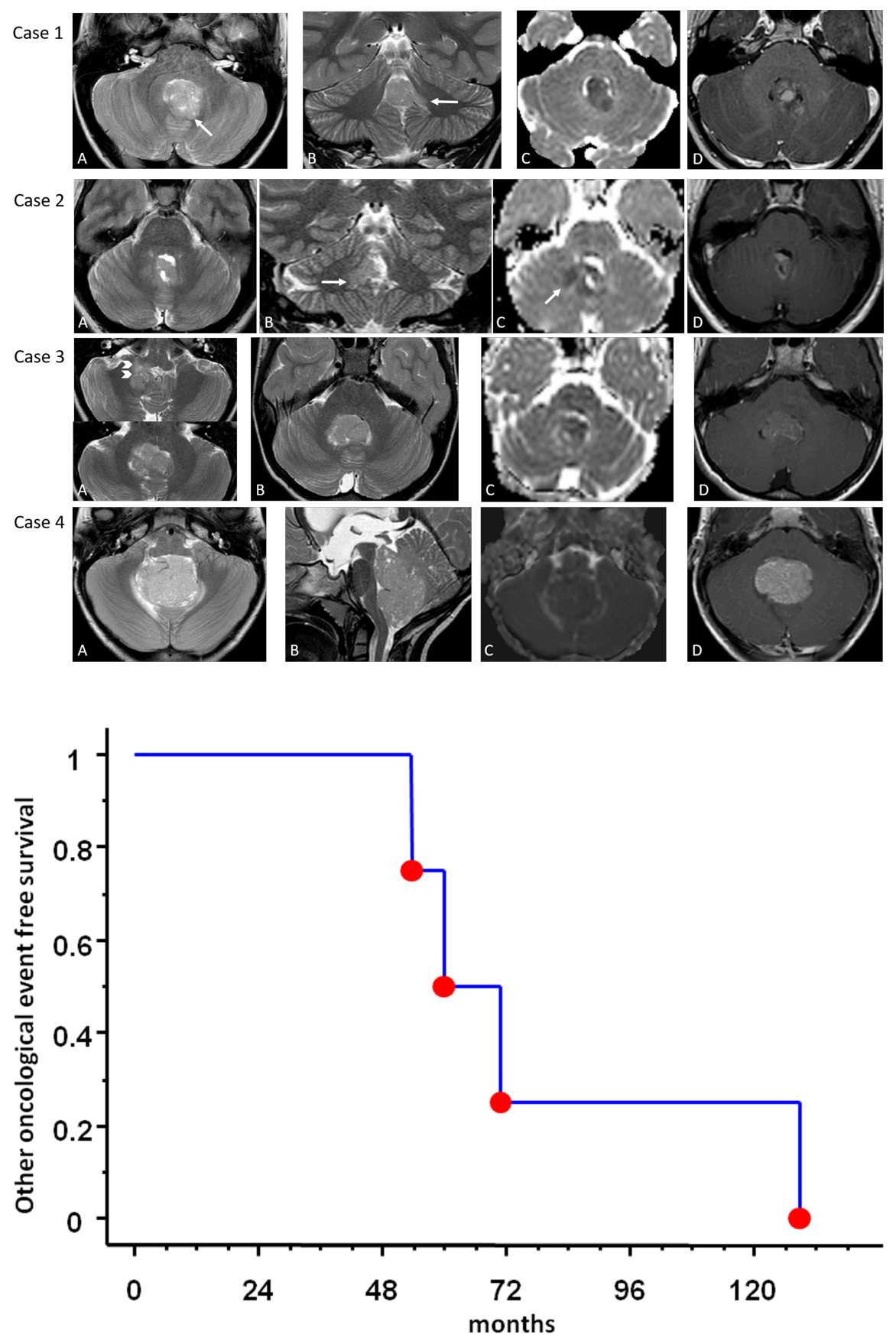

\section{Hosted file}

Table 1. Patients oncological histories, FIQ and present status.docx available at https: //authorea.com/users/347491/articles/479239-medulloblastoma-and-familial-adenomatouspolyposis-good-prognosis-and-good-quality-of-life-in-the-long-term

Hosted file

Table 2 . patient FAP histories.docx available at https://authorea.com/users/347491/articles/ 479239-medulloblastoma-and-familial-adenomatous-polyposis-good-prognosis-and-good- 
quality-of-life-in-the-long-term

\section{Hosted file}

Table 3. family histories.docx available at https://authorea.com/users/347491/articles/ 479239-medulloblastoma-and-familial-adenomatous-polyposis-good-prognosis-and-goodquality-of-life-in-the-long-term 